\title{
The Peer-to-Peer Principle of Inquiry-Based Learning
}

\section{Anke Spies}

The interconnecting peer-to-peer principle appears to be a motivationally beneficial yet demanding component of inquiry-based learning. The principle is the maxim behind the implementation of participatory and inquiry-based learning settings that should stimulate their own professionalization in the context of their studies. After briefly situating the peer-to-peer principle, this article will first explain the ideal of low-threshold network formation in research-related teaching formats based on the tutorial variant and will then discuss the peer-to-peer principle from a group-dynamic point of view. Afterwards, I will outline a model of a moderated peer-to-peer orientation. Finally, I will present a brief look at the inconsistencies inherent in linking the peer-to-peer principle with further maxims of inquiry-based learning.

\subsection{The Ideal in Higher Education Didactics of the Low-Threshold Network}

To begin with, the peer-to-peer principle is a facet of networking and, as such, an attempt at optimization in order to facilitate the sustainable use of resources: Regardless of whether it concerns correlations in information science, the economy, or in an ethnographic view of groups of young people, this principle pursues the notion of optimizing the benefits of the work as a whole through the interaction of close parts of a whole. In the academic

\footnotetext{
A. Spies, Prof. Dr. $(\bowtie)$

Carl von Ossietzky Universität Oldenburg, Fakultät Bildungs- und Sozialwissenschaften, Institut für Pädagogik, Professur für Erziehungswissenschaft, Oldenburg, Germany e-mail: anke.spies@uni-oldenburg.de
} 
didactic setting of inquiry-based learning, students work together as peers in order to improve the benefits of the explorative engagement with the subject matter of their academic studies. The strategy refers to the networking of students of equal educational levels whose learning process should benefit from the different levels of knowledge available within the student body (peers) and from the collaboration. The instructive function of the educator, hereinafter referred to as "principal investigators," recedes into the background. It is replaced by mentoring functions which support the peer-to-peer principle during the process (cf. Pita et al. 2013). The shared research process of the peers benefits from the exchange of existing knowledge, which is bundled and shared. The self-reinforcing contacts optimize the benefits of the student research process (cf. ibid.). Edgcomb et al. (2010) described an additional, possible peer-to-peer relationship: collaborative mentoring as a networking strategy between students who have not yet graduated and doctoral students.

The tutorial peer-to-peer understanding in an academic didactic tradition is based on different degrees of knowledge and, in part, on different degrees of qualification as well and will be examined in greater detail below. At the same time, students in the master's degree who have already provided proof of qualification are nevertheless still counted among the peers in the bachelor's degree program in a discipline. Peer status is acquired by belonging to the same or a similar cohort of a common professional orientation or context.

\subsection{Peer-To-Peer in Tutorials}

Tutorials serve as supplemental courses to regular courses, where the material is reviewed and expanded upon. As an expansion on the learning material that is designed to be largely receptive (and, depending on the subject culture, also discursive), it is primarily new students who are introduced to academic engagement with content and issues in a subjectrelated context, whereby (as a rule) trained students who are professionally supervised by principal investigators and want low-threshold teaching experience pass on the knowledge they have hitherto acquired to subsequent students, thereby simultaneously deepening and thus expanding their professional qualifications.

In tutorial settings of inquiry-based learning, on the other hand, the focus is on the learning process of the students involved: the low-threshold format is intended to facilitate access to an examination of research results and research practices, whereby it is assumed that the approach via peer-mediated content and interactions will increase the willingness to actively engage and will reduce "learning resistances" (Grell 2006, p. 10). Since learning takes place and is initiated within the context of social activities, "when routines do not work, when discrepancies arise between the action problem and solution potential" (Faulstich 1999, p. 32) and learning only then occurs "when individuals encounter obstacles and resistances in their actions" (ibid.), it must nevertheless be expected that "action problems that cannot be overcome with existing competencies" (ibid.) will be encountered along the way towards this goal, which can then become "learning difficulties" (ibid.). 
Students in the expansive learning situation of an inquiry-based learning setting are also engaged at the level of the learning process in overcoming their learning behavior, which tends to be resistant. As long as they are accustomed to defensive learning in particular (ibid., p. 24), the socialization process into research-oriented behavior will be reduced to a "learning imposition" (ibid., p. 25), which should be reduced by situational proximity to the tutorial peers. The guidance of peers who have already overcome their resistance to inquiry-based learning should encourage productive learning processes and the elimination of learning resistance from peers who have begun their studies more recently.

Tutorials for new students as peer-to-peer formats in the receptive as well as the interactive research must be situated within the classification system for inquiry-based learning presented by Rueß et al. (2016): In the exchange between the instructing tutors and their participating peers, a learning gain is expected for both sides of the peer relationship out of their shared engagement with research results and research methods. The same applies to explanations of research processes, which in (small) tutorial group formats should lead to in-depth understanding and competence gains for both peer positions. This is based on the pedagogic premise that not only does the explanation lead to sustained learning processes, the low-threshold setting of the tutorial also leads to explanations that promote the learning processes and that encourage engagement.

Depending on the technical-methodical requirement, the requirement for guidance of the peers who are employed as tutors also increases: Insofar as the support in a tutorial setting is also intended to increase the level of activity of the explicitly researching students, their introduction into higher education didactics requires further intensification since both the independent review of literature in a field of research and applying methods make stringent demands on quality assurance measures, while the head start of the tutors in their capacity as peer may be limited.

In explaining the strategies for guiding and supporting student research, Pita et al. (2013) emphasize that the needs for accompanying support advising be provided from the perspective of the students, who simultaneously advise classmates as peer mentors, so that the positive effects of inquiry-based learning can be realized: "Mentoring undergraduates is distinct from the process of mentoring graduate students. Unique challenges stem from, for example, differences in the students' general level of experience and stage of career development" (ibid., p. 11). The authors point out that enthusiasm, expertise, engagement and a sense of responsibility are crucial for the quality of the work results and cannot be presupposed, but rather require systematic support so that an increase in professionalism can be achieved over the course of the relatively short phase of collaboration.

\subsection{Peer-To-Peer with the Help of Instructing Moderation}

Moderating support of student research along the peer-to-peer principle thus by no means implies easing the burden on the principal investigators postulated by Edgcomb et al. (2010). Rather, according to Pita et al. (2013), the autonomy concept of inquiry-based 
learning requires reliable and closely moderating, protective and encouraging principal investigators, who can reconcile the aspirations, ideals and student possibilities of inquirybased learning. In the peer-to-peer process, which is supported and moderated by principal investigators, students are assisted by a research-experienced person, who pre-structures the group formation process and processes within peer-communication in such a way that the specifics of the group-dynamics can be used didactically or, respectively, such that assistance is available to the group during critical phases in the group-dynamic process (see Box 10.1).

For a professionally and methodically guided, moderated student research group, the orientation phase (forming) is the introduction to the research process, which is followed by the power struggle phase (storming), during which the individual or group research question is clarified. Both phases require guidance or space, or moderation for the negotiation processes and bring with them a potential for conflict that can place the successful

\section{Box 10.1: Group Dynamics}

Since the work of Kurt Lewin (1890-1947), who first researched group processes in the 1930s, the terms "group dynamics" and "team formation" usually draw a distinction between five phases of group formation, which regularly recur in a wide variety of group constellations or on a variety of occasions (cf., inter alia, König and Schattenhofer 2006).

(1) During the orientation phase (forming), the group members come together under similar conditions or on similar occasions, behave cautiously while getting to know one another, follow leadership and have not yet developed a sense of community.

(2) During the confrontation or power struggle phase (storming), which is characterized by negotiation of control, all group participants are engaged in finding and defining their position and role within the group.

(3) The clarifying phase of the confrontation is followed by the familiarization phase (norming). Now cooperation and rule-based collaboration determine the common process, as the strengths and weaknesses of the participants are known and tolerated. A sense of togetherness provides stability. The common rules facilitate a productive collaboration.

(4) On this basis, the group can go into the differentiation phase (performing), during which it is capable of significant achievements. It is at the peak of its working and group process and can distinguish itself from other groups, but also establish contact with them.

(5) During the separation phase (adjourning), these connections are once again severed: The task is done, and interest ebbs or differentiates individually. Reaching the group goal requires that this conclusion be marked. 
course of the research process at risk. Because the group is initially guided in the moderated peer-to-peer setting and only gradually assumes process responsibility for the joint research over the course of the working process, it is able to coordinate its data collection, data analysis and securing of the findings in the research report (largely) autonomously during the familiarization phase (norming) and the differentiation phase (performing). In so doing, the group can analogously "grow together" as a group structure along the peerto-peer principle because process moderation provides a relatively secure framework, in which academic success is not jeopardized by the unsettling forming phase or by the conflict-sparking storming phase. As a component of an expanded peer-to-peer understanding, "adjourning" can be staged as a separation phase, whereby the work results of the current group's research process is passed on to one or more subsequent student groups.

In this setting, the student research group profits from the support provided by the moderating instructor because group principles can be taken into account and made transparent to the group members. In the moderated, research-based student group, the encouragement and development of the individual is the focus of the group process; for the latter to be successful, the professional and dynamic status of the group must be determined before moderating guidance can be progressively reduced or withdrawn over the course of the collaboration.

In my practice of this variant of inquiry-based learning, the following method of working has proven itself: the primary orientation of the higher education didactic setting should facilitate student learning processes in the mode of research that corresponds to currently relevant or, respectively, professionally "significant" (see above) issues, embedded within the context of a long-term project. In addition, structuring aids as well as offers of professional and methodical support are provided. The free choice of topic and method is made by selecting the course (forming). On the one hand, the respective focus is on the findings of previous research groups, which have been transferred to the subsequent group; on the other, this focus is part of the storming, because the new group will continue to modify the content and methods in accordance with their perspectives and interests. Students in a newly beginning research group receive the previous research of their peers (over several semesters) and subsequently situate their own research approaches relative to the existing intermediate results (norming and performing). At the end of their own working process, these peers also formulate further research assignments for subsequent peers, who, in the engagement of their study group, differentiate these assignments/research questions/methodical guidelines and implement them in accordance with their own priorities (adjourning), until they can formulate new assignments themselves.

The respectively active student research groups use both the research reports and excerpts from empirical master's theses by their classmates, which can be written in the research group as a follow-up to research, as a basis for their own research processes. In this receptive format, the peer-to-peer principle may be indirect; however, in this way, the networking of student resources can be utilized well beyond graduation. Here, the peer-topeer principle refers to the work results, which are used again as a starting point for the 
working processes of subsequent peers, which can diffuse both the forming and the storming phases, and which can underpin the norming and performing phases. In this way, the resource of the available student research products continues to steadily grow.

\subsection{Inconsistencies}

Although the method outlined here contradicts the fundamental maxims that have been applied to the most unstructured beginning phase of group processes since Lewin's work, its structural specifications nevertheless meet the requirements of study under the conditions of the Bologna reform. The latter is neither designed for the peer-to-peer principle nor for group processes that follow Lewin's thesis that uncertainty is necessary for the initiation of learning opportunities. The observations of Pita et al. (2013) demonstrate that the thesis of uncertainty as a prerequisite for acquiring new behaviors and attitudes should not be transferred to the student setting of inquiry-based learning, since this can place the positive learning processes at risk.

As a setting that reflects the group dynamic, the alignment with the peer-to-peer principle on the one hand and goal-oriented research on the other should be weighed against one another and the peer-to-peer principle should be distanced from the goals of groupdynamic trainings with claims of promoting self-awareness, since character-forming benefits cannot be measured in credit points. Only the research result - in the sense of the correct methodology and stringent reasoning - can be assessed. Group-dynamic interactions cannot be assessed with credit points and measurable evaluation, which ultimately must be considered in relation to the group-dynamic interventions. In the higher education didactic setting of moderated peer-to-peer research groups, however, group processes are committed to the acquisition of scientific competence and are bound to professional insights into the findings that are produced. Thus, they are part of a systematic professionalization process. In this respect, the peer-to-peer principle must be subordinated to the learning outcomes of inquiry-based learning.

In inquiry-based learning, the peer-to-peer principle demonstrates a series of additional inconsistencies, which likewise arise from the field of tension between the ideals of inquiry-based learning and the current requirements for student learning:

- Peer-to-peer follows the economic intent of generating sustainability in work and networking. However, students are only able to obtain the sustainability benefits during the working process, however, since cooperative and collaborative forms of work require a (group-dynamic) learning process, which leads from possibly different attitudes among the researchers to a common interest in the results.

- The initial learning situation of the students, who are learning through research or, respectively, researching through learning in line with the peer-to-peer principle (cf. Rueß et al. 2016), is heterogeneous in terms of the students' existing professional background knowledge and in terms of the methodical application competence, depending 
on the degree program, phase of study and the composition of the student group, and structured higher education didactic considerations are required so that the heterogeneity of the initial situation in the process can become a resource.

- The postulate of freedom is also opposed by the demand that the findings be of interest to third parties (Huber 2014): Student research should be based on the subject and should by no means be random or incidental, but rather based on significant (cf. Clark 1997) issues, the development of which can provide insight into existing, subjectrelated bodies of knowledge on the one hand and can generate new insights in the sense of scholarship on the other.

With the peer-to-peer principle, the fundamental intention of the higher education didactic setting in inquiry-based learning, which seeks to promote independence and thus personal responsibility in the learning process, appears to multiply: If inquiry-based learning per se is to expand and encourage the motivation to actively and autonomously shape the learning process, the same would be expected of the principle of learning from and through classmates (peers). It is questionable, however, whether such "multiplication" of the motivational postulate acts to underpin the entire format and to what degree the principle can dispense with instruction and supervision by principal investigators. Which framework secures the professional content in the sense of methodical and discursive research accuracy? What risks (of failure) are associated with group-dynamic processes and which structural prerequisites are required pursuant to the measures of the Bologna reform?

It is questionable whether inquiry-based learning along the peer-to-peer principle can dispense with the portion of teaching that provides support and guidance. Peer-to-peer does not absolve educators from the responsibility of securing the learning setting in such a way that certificate-relevant benefits are actually obtained, and the risk of failure is (or can be) minimized. The higher education didactic price for this is technically and methodically justifiable restrictions or relativizations of the freedom to select topics and methods. The benefit, on the other hand, can be the increase in the quality of final theses and the optimization of the theory-practice ratio.

\section{References}

Clark, B. (1997). The modern integration of research activities with teaching and learning. Journal of Higher Education, 68(3), 241-255.

Edgcomb, M. R./Crowe, H. A./Rice, J. D./Morris, S. J./Wolffe, R. J./McConnaughay, K. D. (2010). Peer and near-peer mentoring: Enhancing learning in Summer Research Programs. Council of Undergraduate Research Quarterly, 31(2), 18-25.

Faulstich, P. (1999). Einige Grundfragen zur Diskussion um selbstgesteuertes Lernen. In S. Dietrich,

E. Fuchs-Brüninghoff (Hrsg.), Selbstgesteuertes Lernen-Auf dem Weg zu einer neuen Lernkultur (S. 24-39). Frankfurt/M.: DIE.

Grell, P. (2006). Forschende Lernwerkstatt: Eine qualitative Untersuchung zu Lernwiderständen in der Weiterbildung. Münster: Waxmann. 
Huber, L. (2014). Forschungsbasiertes, Forschungsorientiertes, Forschendes Lernen: Alles dasselbe? Das Hochschulwesen, 62(1+2), 22-29.

König, O./Schattenhofer, K. (2006). Einführung in die Gruppendynamik. Heidelberg: Auer.

Pita, M./Ramirez, C./Joacin, N./Prentice, S./Clarke, C. (2013). Five effective strategies for mentoring undergraduates: Students' perspectives. Council of Undergraduate Research Quarterly, $33(3), 11-15$.

Rueß, J./Gess, C./Deicke, W. (2016). (2016). Forschendes Lernen und forschungsbezogene Lehre empirisch gestützte Systematisierung des Forschungsbezugs hochschulischer Lehre. Zeitschrift für Hochschulentwicklung, 11(2), 23-44.

Open Access This chapter is licensed under the terms of the Creative Commons AttributionNonCommercial-NoDerivatives 4.0 International License (http://creativecommons.org/licenses/bync-nd/4.0/), which permits any noncommercial use, sharing, distribution and reproduction in any medium or format, as long as you give appropriate credit to the original author(s) and the source, provide a link to the Creative Commons licence and indicate if you modified the licensed material. You do not have permission under this license to share adapted material derived from this chapter or parts of it.

The images or other third party material in this chapter are included in the chapter's Creative Commons licence, unless indicated otherwise in a credit line to the material. If material is not included in the chapter's Creative Commons licence and your intended use is not permitted by statutory regulation or exceeds the permitted use, you will need to obtain permission directly from the copyright holder.

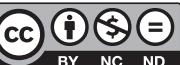

